\title{
A Meta-Analysis on the Relations between EGFR R521K Polymorphism and Risk of Cancer
}

\author{
Yinsheng Wang, Lidan Zha, Dan Liao, and Xiaozhi Li \\ Department of Stomatology, The First Affiliated Hospital of Chongqing Medical University, Chongqing Medical University, \\ No. 1 Yixueyuan Road, Chongqing 400016, China
}

Correspondence should be addressed to Xiaozhi Li; 1043677216@qq.com

Received 7 June 2014; Accepted 9 September 2014; Published 21 October 2014

Academic Editor: Henry Heng

Copyright (C) 2014 Yinsheng Wang et al. This is an open access article distributed under the Creative Commons Attribution License, which permits unrestricted use, distribution, and reproduction in any medium, provided the original work is properly cited.

The EGFR R521K polymorphism has been shown to reduce the activity of EGFR; however, the association between EGFR R521K polymorphism and the risk of cancer remains inconclusive; therefore we performed a meta-analysis to evaluate the relationship between EGFR R521K polymorphism and susceptibility to cancer. Our results suggest that the EGFR R521K polymorphism is not associated with risk of cancer, but the different chemosensitivity to anticancer drugs may need further investigation.

\section{Introduction}

Cancer is one of the leading causes of death in humans worldwide. It is not a single, well-defined, but a generalized term of heterogeneous diseases including more than a hundred types. Although each type presents an independent feature, the essential pathological characteristics are referred to as aberrant cell proliferation, invasion, and migration.

Many studies have investigated the role of human epidermal growth factor receptor (EGFR, also known as HER1 or ErbB1) in cancer. Abnormal expression or activity of EGFR observed in many types of cancer, like breast cancer, colorectal cancer, non-small-cell lung cancer, head and neck squamous cell carcinoma, has been considered as an important marker in tumorigenesis, which resulted in more aggressive tumor phenotype, higher recurrence rate, and poorer prognosis [1-4].

EGFR plays a crucial role in cancer because it is a receptor for a wide variety of ligands including amphiregulin, betacellulin, EGF, epigen, epiregulin, heparin binding EGF-like growth factor (HB-EGF), and type $\alpha$ transforming growth factor (TGF- $\alpha$ ). The binding of ligand triggers the activation of MAPK, PI3K/Akt/mTOR, and JAK/STAT downstream signalling pathway, which are responsible for regulation of numerous tumorigenic functions such as cancer cell proliferation, antiapoptosis, and metastasis [5-8].
The EGFR R521K polymorphism, also termed rs11543848, rs2227983, R497K, or $142285 \mathrm{G}>\mathrm{A}$, has a guanine [G] to adenine $[\mathrm{A}]$ mutation leading to an arginine $[\mathrm{R}]$ to lysine $[\mathrm{K}]$ substitution at codon 521 located in the CR2 domain and resulted in an attenuated activity of the receptor [9, 10]. Several reports have explored the involvement of R521K polymorphism in risk of cancer, but these reports presented inconclusive and controversial results. Therefore, we conducted a meta-analysis on the published studies to evaluate the effect of EGFR R521K polymorphism with the risk of cancer.

\section{Material and Methods}

2.1. Publication Retrieval. A comprehensive search in PubMed, Web of Science, OVID, and Cochrane Library regarding R521K polymorphism was performed. The following search words were used: "EGFR," "ErbBl," "HER1," "polymorphism," "R497K," "R521K," "rs11543848," "rs2227983," "142285G>A," and "cancer." We also traced the references of the articles and reviews to include the potentially eligible original reports.

2.2. Inclusion and Exclusion Criteria. All articles were included in the meta-analysis if they were (1) case-control 
studies, (2) studies on the relationship of R521K polymorphism and cancer risk, (3) sufficient data for the frequencies of alleles and genotypes in cases and controls.

Articles were excluded if they were (1) not related to cancer, (2) of insufficient information, (3) animal, bacteria, or cell line studies, (4) studies on the basis of family or twins rather than random general ones, and (5) repeatedly published data.

2.3. Data Extraction. Two investigators extracted the information independently including first author, journal, year of publication, country of origin, cancer type, genotyping method, sample size, source of control groups, frequency of genotypes and alleles in cases and controls, and the HardyWeinberg equilibrium (HWE) of genotype distribution in controls. Any disagreements between the two investigators were resolved by consensus.

2.4. Statistical Analysis. HWE that has not been reported in the literatures was assessed with the De Finetti program (http://ihg.gsf.de/cgi-bin/hw/hwal.pl). The odds ratios (ORs) and the corresponding 95\% confidence intervals (CIs) were used to assess the association between the R521K polymorphism and cancer risk. The pooled ORs were performed in allelic genetic model (A versus $\mathrm{G}$ ), codominant model (AA versus $G G$ and $G A$ versus $G G$ ), recessive genetic model (AA versus $G A+G G)$, and dominant genetic model (AA + GA versus $G G)$. Subgroup analyses were also conducted based on ethnicity and cancer type. Heterogeneity between studies was checked by Chi-square based $Q$ statistics, and the $I^{2}$ index which expresses the percentage of the total variation across studies was also tested. If the $P$ value was $<0.05$ or the $I^{2}$ index was $\geq 50 \%$, the random-effect model was adopted; otherwise the fixed-effect model was adopted [24]. Publication bias was evaluated using Begg's funnel plots and Egger's test $[25,26]$. Statistical analyses were performed with Review Manager (version 5.2; Cochrane Collaboration, Oxford, UK) and Stata software (version 12; Stata Corporation, College Station, TX, USA).

\section{Results}

3.1. Characteristics of Included Studies. After a thorough scan of the databases, 68 eligible studies related to EGFR R521K polymorphism were identified. 30 of them were initially excluded by title or abstract; 25 of them were excluded due to case studies. As a consequence, 13 studies containing 7328 cases and 8455 controls were included in this meta-analysis (Figure 1). Among the 13 studies, 4 studies were related to breast cancer $[12,20,22,23], 3$ studies were related to colorectal cancer $[11,18,21], 2$ studies each were related to gastric carcinoma and hepatocellular cancer $[13,14,16,17]$, and each related to lung cancer and thyroid cancer $[15,19]$. The ethnicities of subjects in 3 studies were Arabs and Caucasian, respectively; 5 studies were Asian, 1 study was Mexican and Indian, respectively. Nine studies recruited controls based on population, 3 studies recruited controls with respect to gender and age of cases, and 1 study took subjects as controls in population based and matching-criteria based manner.
The distributions of the R521K polymorphism genotype in all control groups of the studies were in accordance with HWE. Detailed characteristics of the selected studies were shown in Table 1 .

3.2. Quantitative Synthesis. The summary of the results for the association between EGFR R521K polymorphism and cancer susceptibility was shown in Table 2 . In the overall analysis, no association between $\mathrm{R} 521 \mathrm{~K}$ polymorphism and cancer risk was found in all genetic models (A versus $G$ : $\mathrm{OR}=1.06,95 \% \mathrm{CI}: 0.95,1.18, P_{H}<0.0001, I^{2}=69$, and $P=0.28$; AA versus $\mathrm{GG}, \mathrm{OR}=0.85,95 \% \mathrm{CI}: 0.74,0.99, P_{H}$ $=0.25, I^{2}=19$, and $P=0.12$; AA versus $\mathrm{GA}+\mathrm{GG}: \mathrm{OR}=$ 0.99, 95\% CI: 0.91, 1.08, $P_{H}=0.84, I^{2}=0$, and $P=0.80$; GA versus GG: $\mathrm{OR}=1.04,95 \% \mathrm{CI}: 0.87,1.25, P_{H}<0.00001$, $I^{2}=74$, and $P=0.67$; and AA + GA versus $\mathrm{GG}: \mathrm{OR}=1.02$, 95\% CI: $0.86,1.21, P_{H}<0.0001, I^{2}=73$, and $\left.P=0.84\right)$. In subgroup analysis, only a significant association between R521K polymorphism and reduced cancer risk was observed in the allelic genetic model in gastric cancer, but not in other genetic models (A versus $\mathrm{G}$ : $\mathrm{OR}=1.43,95 \% \mathrm{CI}$ : 1.19, 1.72, $P_{H}$ $=0.49, I^{2}=0$, and $\left.P=0.0001\right)$. No significant difference in other types of cancer and ethnicities was found.

3.3. Sensitivity and Metaregression Analyses. There was only low between-study heterogeneity in homozygote model (AA versus GG) and recessive genetic model (AA versus GA + GG) both in overall and subgroup analyses, but high heterogeneity was observed in allelic genetic model (A versus $G)$, heterozygote model (GA versus GG), and dominant genetic model (AA + GA versus GG). Therefore the sensitivity analysis and metaregression analysis were performed to clarify the source of heterogeneity. In the sensitivity analysis, a single study was omitted each time to investigate the influence of the individual data on the pooled ORs. No significant alteration occurred in this procedure. In the metaregression analysis, neither cancer type nor ethnicity could explain the significant between-study heterogeneity.

3.4. Publication Bias. The results of the Begg funnel plots indicated no evidence of obvious asymmetry. The results of Egger's test also suggested little evidence of publication bias in the overall analysis (A versus G: $P=0.285$; AA versus GG: $P=0.691 ; \mathrm{AA}+\mathrm{GA}$ versus $\mathrm{GG}: P=0.713$; AA versus $\mathrm{GA}+$ GG: $P=0.419$; and GA versus GG: $P=0.319)$.

\section{Discussion}

It is well documented that the genetic polymorphism may contribute to susceptibility to cancer. In the current study, we reviewed all literatures regarding EGFR R521K polymorphism in cancer and conducted a meta-analysis to identify the association between the $\mathrm{R} 521 \mathrm{~K}$ polymorphism and the risk of cancer. The results revealed that no significant association was observed between R $521 \mathrm{~K}$ polymorphism and risk of cancer, except a statistical difference between A and $G$ allele frequency in gastric cancer. The difference may be of low statistical power in view of the circumstance that there were only two articles related to gastric cancer. 


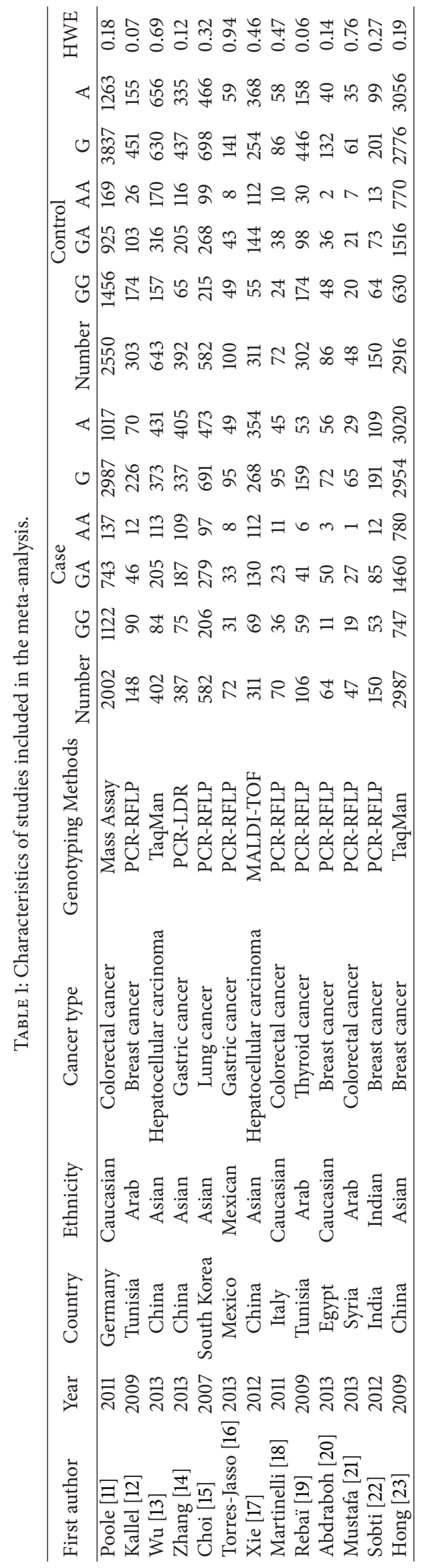




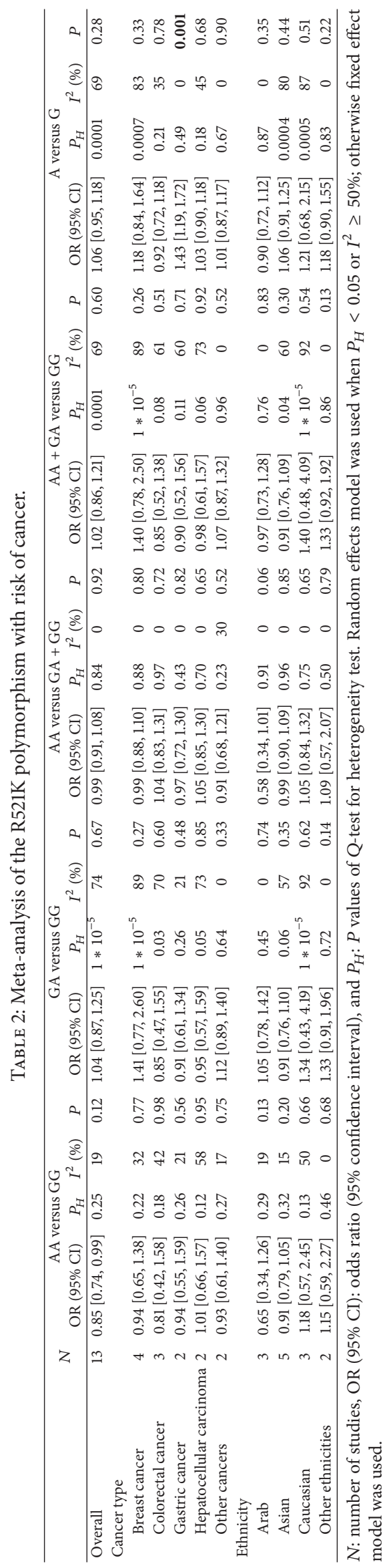




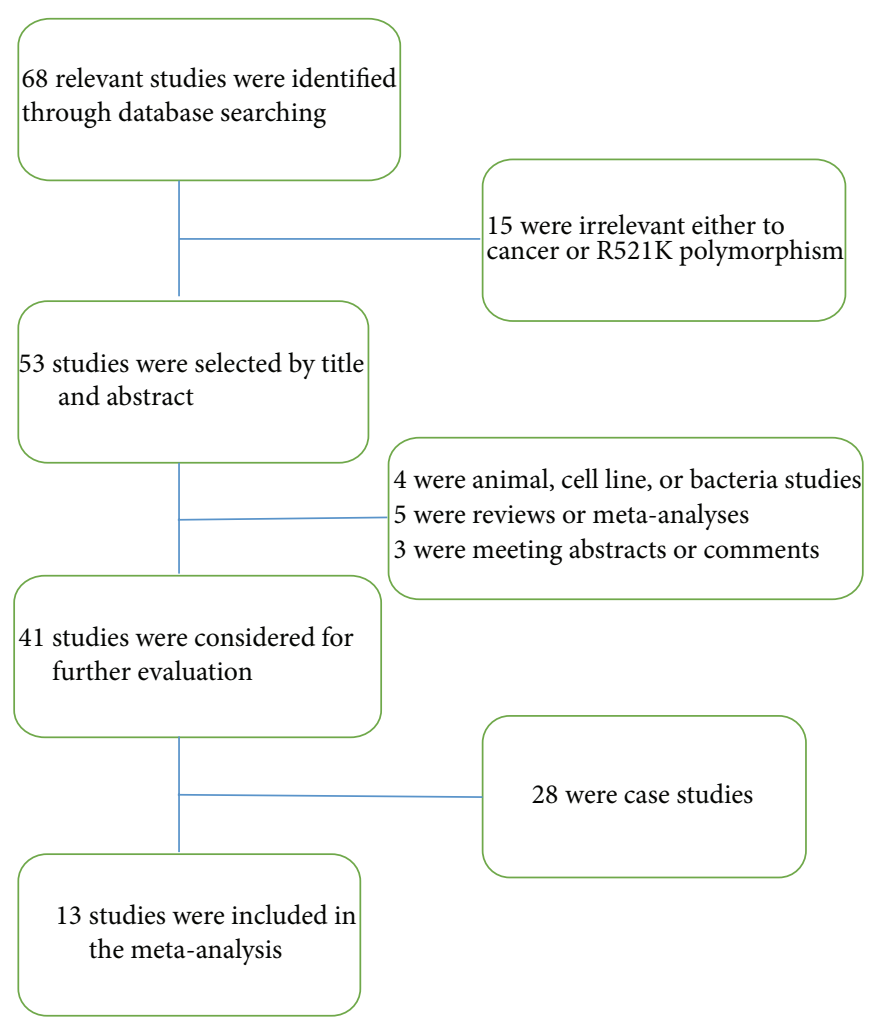

FIgURE 1: The flow diagram of the identification of studies.

EGFR is a member of the ErbB transmembrane receptors tyrosine kinase (RTK) family, whose members share a highly conserved extracellular ligand binding domain, a single-helix transmembrane segment, a tyrosine kinase juxtamembrane segment, and a regulatory carboxyterminal tail. The extracellular region of EGFR is composed of four domains: Domains I (L1), II (S1 or CR1), III (L2), and IV (S2 or CR2). L1 and L2 are members of the leucine-rich repeat family and are responsible for ligand binding. CR1 and CR2 are homologous cysteinerich domains. In the absence of ligand, a $\sim 25 \AA \beta$-hairpin loop extends from CR1 to contact the juxtamembrane region of CR2 and forms a tether structure. When ligand binds, the CR1/CR2 complex separates and the L1/CR1 composes a new binding site $[27,28]$. The CR1/CR2 complex plays a role in determining the relative position of the EGFR dimers during ligand binding [29].

The R521K polymorphism is located in the CR2 domain and presents a lower affinity to TGF- $\alpha$, a ligand which is related to cell proliferation, differentiation, and invasion after binding to EGFR. However, another study demonstrated that the CR1/CR2 tether structure exerted only a limited effect on EGF binding, EGFR activation, and cell signalling [30]. Take our result into consideration, we infer that the R521K polymorphism of EGFR may not be a critical factor in determining susceptibility to cancer; this conclusion is consistent with another meta-analysis indicating that the R $521 \mathrm{~K}$ polymorphism is not associated with risk of breast cancer [31]. Nevertheless, several studies have reported that the $\mathrm{R} 521 \mathrm{~K}$ polymorphism alone or in combination with a longer $(\mathrm{CA})_{n}$ repeat polymorphism is associated with a better survival rate in cancer [32-36], while others report a negative relevance [37]. Furthermore, some studies have reported that the R521K polymorphism is associated with favorable outcomes in cetuximab-based and 5-FU-based chemotherapy $[32,35,38-41]$ but shows negative correlation in gefitinibbased chemotherapy [37, 42, 43]. Not only indicate these results a complex mechanism in gene-gene interaction in regulating the function of EGFR, but also the different profiles of clinical response to chemotherapy suggest that the R521K polymorphism may be involved in the field of pharmacogenetics. In addition, the results also adduce a new evidence for the evolutionary mechanism of cancer; that is, single nucleotide polymorphism in individual gene, whether it would affect cancer cell proliferation or not, may exercise only a little influence on chromosome instability (CIN), and for this reason, the cancer progression is not altered remarkably $[44,45]$.

Studying heterogeneity was a considerable problem in our meta-analysis. The heterogeneity existed in allelic genetic model (A versus $G$ ), heterozygote model (GA versus GG), and dominant genetic model (AA + GA versus GG) in overall and subgroup analysis. The metaregression analysis did not identify the source of heterogeneity. In sensitivity analysis, heterogeneity reduced after one literature was excluded, but the pooled ORs did not alter remarkably, implying that the results were statistically stable and reliable. The Begg funnel plot and Egger's test were also negative for publication bias.

There were some limitations in our meta-analysis. First, our meta-analysis was based on only 13 studies including a small sample size; this may lead to a relatively low 
statistical power, especially in subgroup analysis. Second, not all the sources of controls were population based; this may induce deviations from the overall population. Third, no gene-environment or gene-gene interactions were considered which may be involved in the susceptibility to cancer. Fourth, the relation between R521K polymorphism and the chemosensitivity of anticancer drugs remains to be elucidated.

In conclusion, there is no significant association between EGFR R521K polymorphism and risk of cancer. However, further studies based on larger, stratified case-control populations and the effect of gene-gene, gene-environment, and the chemosensitivity of anticancer drugs are still needed to be evaluated.

\section{Conflict of Interests}

The authors declare that there is no conflict of interests regarding the publication of this paper.

\section{Acknowledgment}

This work was supported by the National Key Clinical Specialties Construction Program of China.

\section{References}

[1] R. I. Nicholson, J. M. W. Gee, and M. E. Harper, "EGFR and cancer prognosis," European Journal of Cancer, vol. 37, supplement 4, pp. S9-S15, 2001.

[2] M. W. Saif, "Colorectal cancer in review: the role of the EGFR pathway," Expert Opinion on Investigational Drugs, vol. 19, no. 3, pp. 357-369, 2010.

[3] P. M. Forde and D. S. Ettinger, "Targeted therapy for non-smallcell lung cancer: past, present and future," Expert Review of Anticancer Therapy, vol. 13, no. 6, pp. 745-758, 2013.

[4] F. Montemurro and M. Scaltriti, "Biomarkers of drugs targeting HER-family signalling in cancer," Journal of Pathology, vol. 232, no. 2, pp. 219-229, 2014.

[5] A. W. Burgess, H.-S. Cho, C. Eigenbrot et al., "An open-andshut case? Recent insights into the activation of EGF/ErbB receptors," Molecular Cell, vol. 12, no. 3, pp. 541-552, 2003.

[6] W. A. Cooper, D. C. Lam, S. A. O’Toole, and J. D. Minna, "Molecular biology of lung cancer," Journal of Thoracic Disease, vol. 5, pp. S479-S490, 2013.

[7] C. R. Chong and P. A. Jänne, "The quest to overcome resistance to EGFR-targeted therapies in cancer," Nature Medicine, vol. 19, no. 11, pp. 1389-1400, 2013.

[8] G. G. Gomez, J. Wykosky, C. Zanca, F. B. Furnari, and W. K. Cavenee, "Therapeutic resistance in cancer: microRNA regulation of EGFR signaling networks," Cancer Biology and Medicine, vol. 10, no. 4, pp. 192-205, 2013.

[9] T. Moriai, M. S. Kobrin, C. Hope, L. Speck, and M. Korc, "A variant epidermal growth factor receptor exhibits altered type $\alpha$ transforming growth factor binding and transmembrane signaling," Proceedings of the National Academy of Sciences of the United States of America, vol. 91, no. 21, pp. 10217-10221, 1994.

[10] T. Moriai, M. S. Kobrin, and M. Korc, "Cloning of a variant epidermal growth factor receptor," Biochemical and Biophysical Research Communications, vol. 191, no. 3, pp. 1034-1039, 1993.
[11] E. M. Poole, K. Curtin, L. Hsu et al., "Genetic variability in EGFR, Src and HER2 and risk of colorectal adenoma and cancer," International Journal of Molecular Epidemiology and Genetics, vol. 2, no. 4, pp. 300-315, 2011.

[12] I. Kallel, M. Rebai, A. Khabir, N. R. Farid, and A. Rebaï, "Genetic polymorphisms in the egfr (R521K) and estrogen receptor (T594T) genes, EGFR and erbb-2 protein expression, and breast cancer risk in tunisia," Journal of Biomedicine and Biotechnology, vol. 2009, Article ID 753683, 6 pages, 2009.

[13] J. Wu, W. Zhang, A. Xu et al., "Association of epidermal growth factor and epidermal growth factor receptor polymorphisms with the risk of hepatitis b virus-related hepatocellular carcinoma in the population of north China," Genetic Testing and Molecular Biomarkers, vol. 17, no. 8, pp. 595-600, 2013.

[14] J. Zhang, Z. Zhan, J. Wu et al., "Association among polymorphisms in EGFR gene exons, lifestyle and risk of gastric cancer with gender differences in Chinese Han subjects," PLOS ONE, vol. 8, no. 3, Article ID e59254, 2013.

[15] J. E. Choi, S. H. Park, K. M. Kim et al., "Polymorphisms in the epidermal growth factor receptor gene and the risk of primary lung cancer: a case-control study," BMC Cancer, vol. 7, article 199, 2007.

[16] J. H. Torres-Jasso, A. R. Bustos-Carpinteyro, M. E. Marín et al., "Analysis of the polymorphisms EGFR-R521K and ERBB2I655V in Mexican patients with gastric cancer and premalignant gastric lesions," Revista de Investigación Clínica, vol. 65, no. 2, pp. 150-155, 2013.

[17] J.-X. Xie, J.-H. Yin, Q. Zhang et al., "Association of genetic polymorphisms of key molecules in JAK/STAT signaling pathway with susceptibility of hepatocellular carcinoma," Zhonghua Liu Xing Bing Xue Za Zhi, vol. 33, no. 2, pp. 215-219, 2012.

[18] M. Martinelli, G. Ugolini, L. Scapoli et al., "The EGFR R521K polymorphism influences the risk to develop colorectal cancer," Cancer Biomarkers, vol. 8, no. 2, pp. 61-65, 2011.

[19] M. Rebaï, I. Kallel, F. Hamza et al., "Association of EGFR and HER2 polymorphisms with risk and clinical features of thyroid cancer," Genetic Testing and Molecular Biomarkers, vol. 13, no. 6, pp. 779-784, 2009.

[20] N. R. Abdraboh, H. H. Shehata, M. B. Ahmed, and F. A. Bayoumi, "HER1 R497K and HER2 I655V polymorphisms are linked to development of breast cancer," Disease Markers, vol. 34, no. 6, pp. 407-417, 2013.

[21] O. H. Mustafa, A. R. Hamzeh, L. Ghabreau, N. Akil, A.E. Almoustafa, and A. Alachkar, "Allele frequencies of the epidermal growth factor receptors polymorphism R521K in colorectal cancer patients and healthy subjects indicate a riskreducing effect of K521 in Syrian population," North American Journal of Medical Sciences, vol. 5, no. 3, pp. 202-206, 2013.

[22] R. C. Sobti, M. Askari, M. Nikbakht, N. Singh, S. C. Sharma, and A. M. Abitew, "Genetic variants of EGFR (142285>A) and ESR1 (2014>A) gene polymorphisms and risk of breast cancer," Molecular and Cellular Biochemistry, vol. 369, no. 1-2, pp. 217225, 2012.

[23] Y.-S. Hong, S. L. Deming, Y.-T. Gao et al., "A two-stage casecontrol study of EGFR polymorphisms and breast cancer risk," Cancer Epidemiology Biomarkers \& Prevention, vol. 18, no. 2, pp. 680-683, 2009.

[24] R. DerSimonian and N. Laird, "Meta-analysis in clinical trials," Controlled Clinical Trials, vol. 7, no. 3, pp. 177-188, 1986.

[25] C. B. Begg and M. Mazumdar, "Operating characteristics of a rank correlation test for publication bias," Biometrics, vol. 50, no. 4, pp. 1088-1101, 1994. 
[26] M. Egger, G. D. Smith, M. Schneider, and C. Minder, "Bias in meta-analysis detected by a simple, graphical test," British Medical Journal, vol. 315, no. 7109, pp. 629-634, 1997.

[27] K. M. Ferguson, "Structure-based view of epidermal growth factor receptor regulation," Annual Review of Biophysics, vol. 37, pp. 353-373, 2008.

[28] A. Arkhipov, Y. Shan, R. Das et al., "Architecture and membrane interactions of the EGF receptor," Cell, vol. 152, no. 3, pp. 557569, 2013.

[29] P. Liu, T. E. Cleveland IV, S. Bouyain, P. O. Byrne, P. A. Longo, and D. J. Leahy, "A single ligand is sufficient to activate EGFR dimers," Proceedings of the National Academy of Sciences of the United States of America, vol. 109, no. 27, pp. 10861-10866, 2012.

[30] D. Mattoon, P. Klein, M. A. Lemmon, I. Lax, and J. Schlessinger, "The tethered configuration of the EGF receptor extracellular domain exerts only a limited control of receptor function," Proceedings of the National Academy of Sciences of the United States of America, vol. 101, no. 4, pp. 923-928, 2004.

[31] Q. Zheng, R. Chen, L. Luan, J. Li, and S. Gao, “The polymorphism of EGFR 142285G > A exerts no risk effect on breast cancer," Tumor Biology, vol. 35, no. 3, pp. 2383-2389, 2014.

[32] W.-S. Wang, P.-M. Chen, T.-J. Chiou et al., "Epidermal growth factor receptor R497K polymorphism is a favorable prognostic factor for patients with colorectal carcinoma," Clinical Cancer Research, vol. 13, no. 12, pp. 3597-3604, 2007.

[33] E. Bandrés, R. Barricarte, C. Cantero et al., "Epidermal growth factor receptor (EGFR) polymorphisms and survival in head and neck cancer patients," Oral Oncology, vol. 43, no. 7, pp. 713719, 2007.

[34] H. Sasaki, K. Okuda, S. Shimizu et al., "EGFR R497K polymorphism is a favorable prognostic factor for advanced lung cancer," Journal of Cancer Research and Clinical Oncology, vol. 135, no. 2, pp. 313-318, 2009.

[35] Y.-Y. Hsieh, C.-H. Tzeng, M.-H. Chen, P.-M. Chen, and W.S. Wang, "Epidermal growth factor receptor R521K polymorphism shows favorable outcomes in KRAS wild-type colorectal cancer patients treated with cetuximab-based chemotherapy," Cancer Science, vol. 103, no. 4, pp. 791-796, 2012.

[36] M. S. Leite, L. C. Giacomin, D. N. Piranda et al., "Epidermal growth factor receptor gene polymorphisms are associated with prognostic features of breast cancer," BMC Cancer, vol. 14, article 190, 2014.

[37] F. Ma, T. Sun, Y. Shi et al., "Polymorphisms of EGFR predict clinical outcome in advanced non-small-cell lung cancer patients treated with Gefitinib," Lung Cancer, vol. 66, no. 1, pp. 114-119, 2009.

[38] L. Dahan, E. Norguet, M.-C. Etienne-Grimaldi et al., "Pharmacogenetic profiling and cetuximab outcome in patients with advanced colorectal cancer," BMC Cancer, vol. 11, article 496, 2011.

[39] G. Lurje, F. Nagashima, W. Zhang et al., "Polymorphisms in cyclooxygenase-2 and epidermal growth factor receptor are associated with progression-free survival independent of Kras in metastatic colorectal cancer patients treated with singleagent cetuximab," Clinical Cancer Research, vol. 14, no. 23, pp. 7884-7895, 2008.

[40] C.-Y. Lai, F.-C. Sung, L.-L. Hsieh et al., "Associations between genetic polymorphisms of epidermal growth factor receptor (EGFR) and survival of colorectal cancer (CRC) patients treated with 5-fluorouracil-based chemotherapy," Annals of Surgical Oncology, vol. 20, no. 3, pp. S599-S606, 2013.
[41] W. Zhang, D. J. Park, B. Lu et al., "Epidermal growth factor receptor gene polymorphisms predict pelvic recurrence in patients with rectal cancer treated with chemoradiation," Clinical Cancer Research, vol. 11, no. 2I, pp. 600-605, 2005.

[42] G. Liu, S. Gurubhagavatula, W. Zhou et al., "Epidermal growth factor receptor polymorphisms and clinical outcomes in nonsmall-cell lung cancer patients treated with gefitinib," Pharmacogenomics Journal, vol. 8, no. 2, pp. 129-138, 2008.

[43] M. Shitara, H. Sasaki, K. Yokota et al., "Polymorphisms in intron 1 of the EGFR gene in non-small cell lung cancer patients," Experimental and Therapeutic Medicine, vol. 4, no. 5, pp. 785789, 2012.

[44] S. D. Horne, S. A. Pollick, and H. H. Q. Heng, "Evolutionary mechanism unifies the hallmarks of cancer," International Journal of Cancer, 2014.

[45] H. H. Heng, S. W. Bremer, J. B. Stevens et al., "Chromosomal instability (CIN): what it is and why it is crucial to cancer evolution," Cancer and Metastasis Reviews, vol. 32, no. 3-4, pp. 325-340, 2013. 

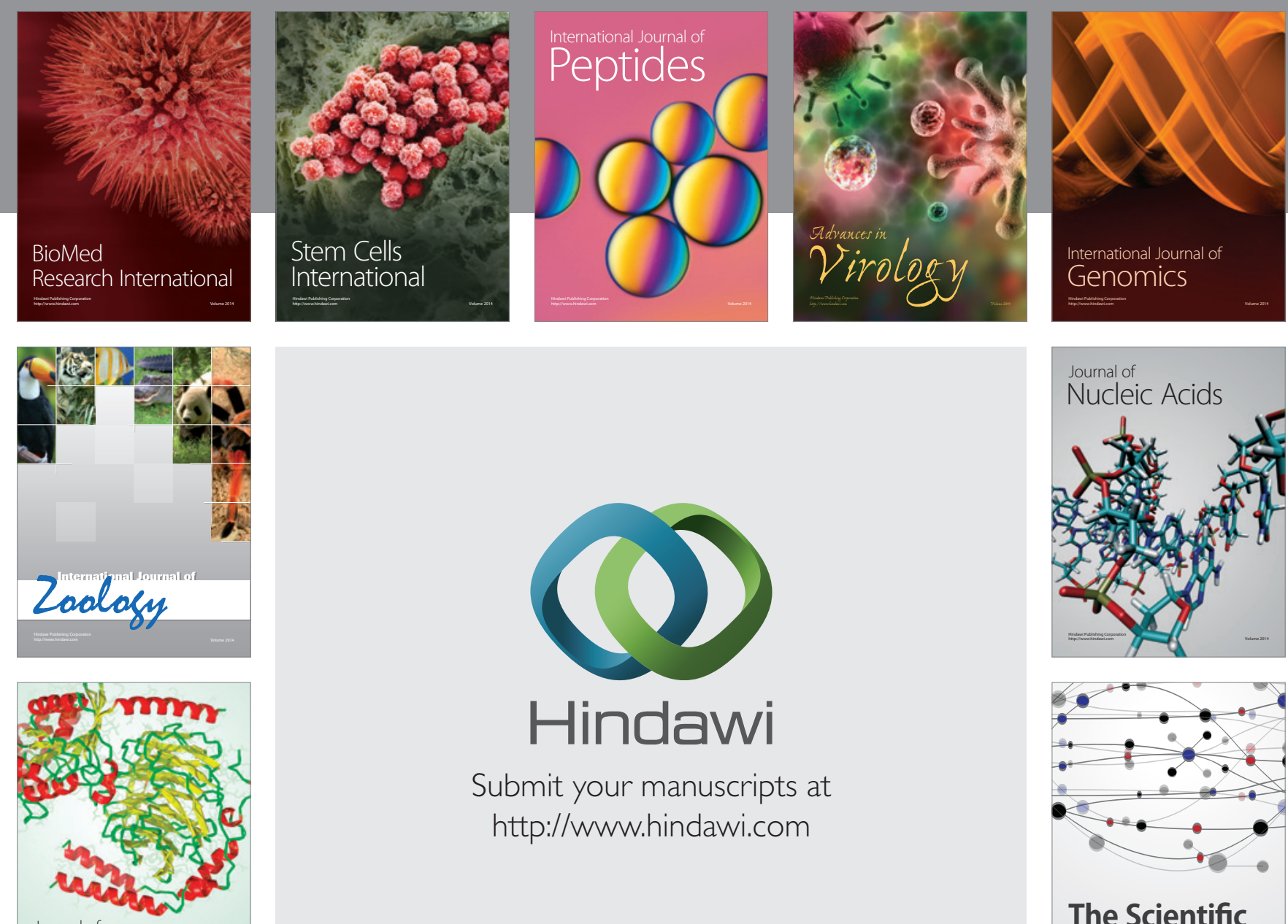

Submit your manuscripts at

http://www.hindawi.com

Journal of
Signal Transduction
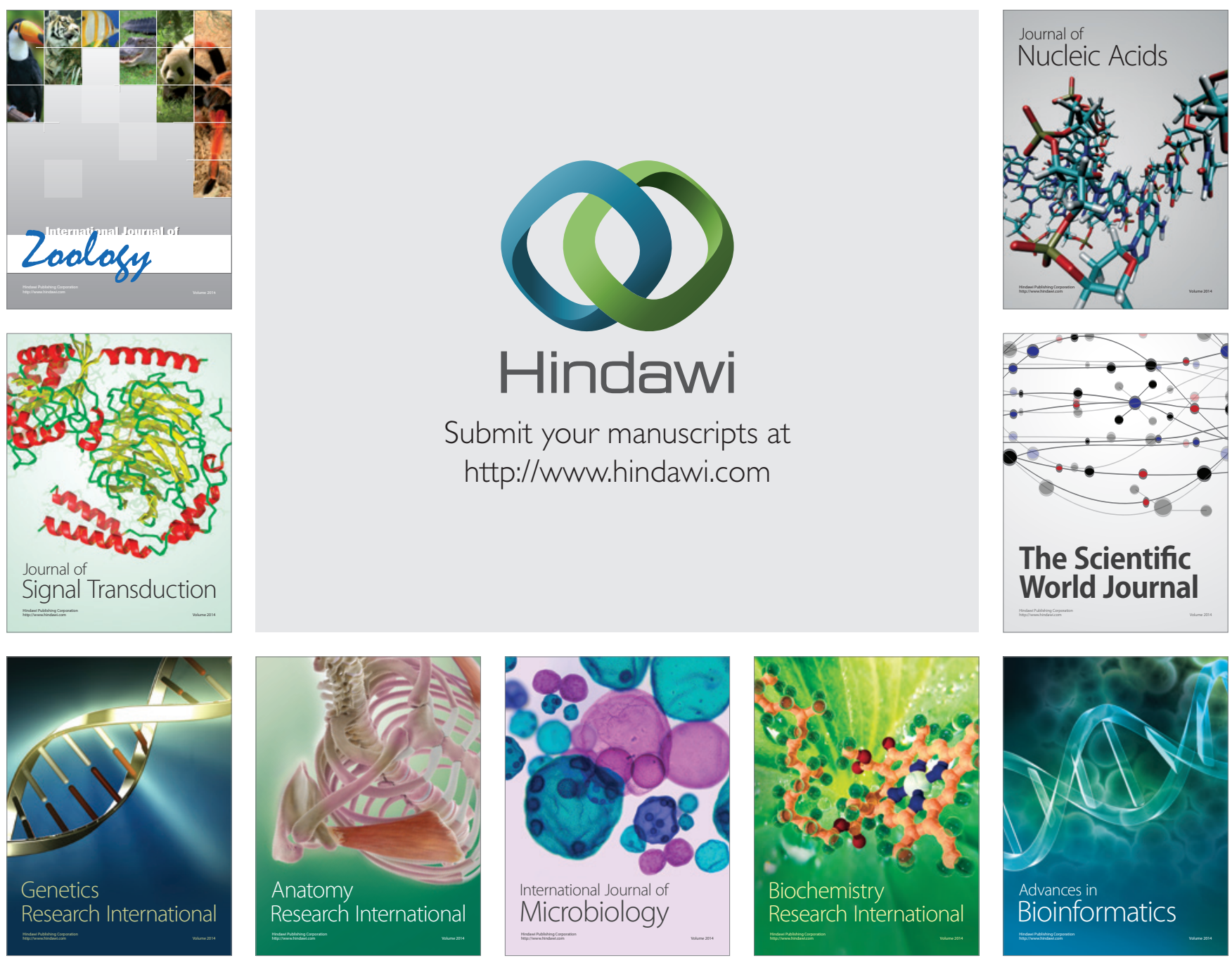

The Scientific World Journal
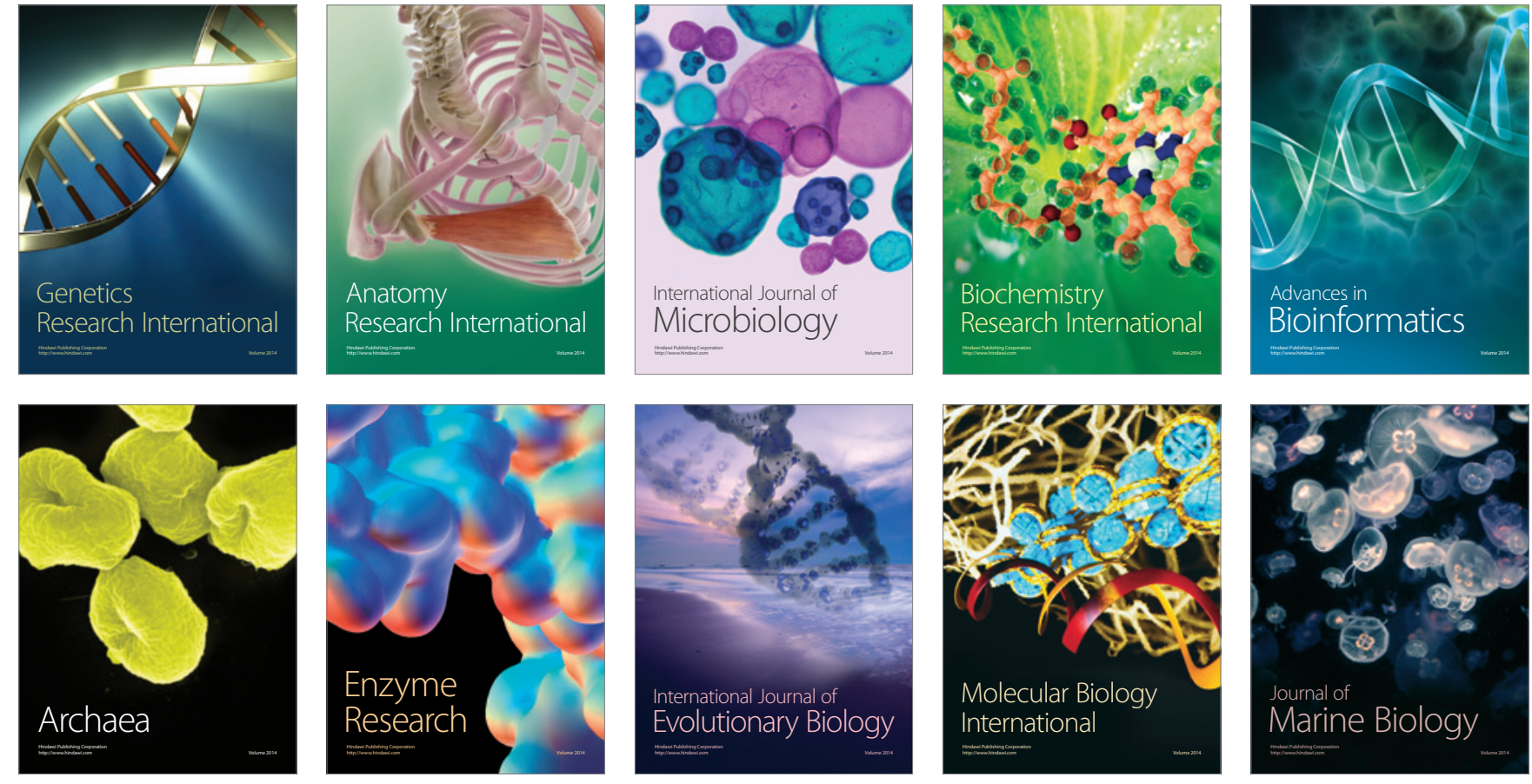